\title{
Secondary Fahr's Disease: A Consequence of Post-Thyroidectomy Hypoparathyroidism
}

\author{
Najia Mahmood, Jahanzaib Hamid, Faramarz Khan, Muhammad Khurram, Mubashar Alam \\ Rawalpindi Medical University and Allied Hospitals, Department of Medicine, Rawalpindi, Pakistan
}

Received: 01/04/2019

Accepted: 02/04/2019

Published: 04/06/2019

\begin{abstract}
How to cite this article: Mahmood N, Hamid J, Khan F, Khurram M, Alam M. Secondary Fahr's disease: a consequence of post-thyroidectomy hypoparathyroidism. EJCRIM 2019;6: doi:10.12890/2019_001109.
\end{abstract}

Conflicts of Interests: The Authors declare that there are no competing interests.

This article is licensed under a Commons Attribution Non-Commercial 4.0 License

\section{ABSTRACT}

Objective: The objective of this case report is to emphasize the importance of considering uncommon conditions like Fahr's disease in the differential diagnosis of seizures and cognitive impairment, especially in patients with a history of thyroidectomy.

Material and Methods: A 56-year-old woman who had undergone subtotal thyroidectomy 25 years previously presented with movement disorder and cognitive impairment secondary to hypoparathyroidism. A CT scan of the brain showed pathognomonic bilateral calcification in the basal ganglia, thalamus and cerebellar nuclei.

Result: The patient was diagnosed with Fahr's disease caused by post-thyroidectomy hypoparathyroidism and successfully managed with oral calcium, carbidopa/levodopa and haloperidol.

Conclusion: We recommend the routine use of CT scanning in the long-term follow-up of post-thyroidectomy patients.

\section{LEARNING POINTS}

- CT scans of the brain should be routinely carried out as part of long-term follow-up after thyroidectomy.

- Cognitive impairment and/or seizures should also be investigated using brain imaging.

- Taking a detailed history is a cornerstone of diagnosis in internal medicine.

\section{KEYWORDS}

Fahr's disease, CT scan brain, hypoparathyroidism, thyroidectomy, basal ganglia

\section{BACKGROUND}

Fahr's disease has a very low prevalence (<1 per million population) but is considered under-reported ${ }^{[1]}$. The disease is characterized by bilateral symmetrical calcium deposition in areas of the brain associated with movement control like the basal ganglia and adjacent parenchyma such as the dentate nuclei, putamen, thalami, cerebral cortex, subcortical white matter, hippocampus and cerebellum ${ }^{[2]}$. Usually idiopathic, it has however been reported to be associated with disorders of calcium and phosphate metabolism. Clinical manifestations depend on the area of the brain affected. Treatment is mainly symptomatic. The aim of this case report is to emphasize the importance of obtaining CT imaging in patients with metabolic disorders such as hypoparathyroidism.

\section{CASE PRESENTATION}

In February 2019, a 56-year-old woman presented to our tertiary care hospital with a 1-year history of repeated episodes of generalized tonic-clonic seizures, irritability, involuntary body movements primarily of the upper limbs, dysphagia and insomnia. Her past medical history was insignificant except for subtotal thyroidectomy 25 years previously. 
Symptoms had begun insidiously with involuntary movement of the upper limbs which was progressive in nature. The family had also noticed ongoing changes in her overall behaviour, including forgetfulness, irritability, disorientation and dysphoria. Later, she also developed dysarthric speech. The family visited a neurologist and the woman was prescribed anti-epileptics and anti-psychotics, with some improvement. However, during the 3 months before presentation at our hospital, the patient's symptoms had worsened with advanced limitation of movement, so all medications were stopped. The family history was unremarkable for any neurological disease or similar disorder. Her examination showed normal vital signs and a normal neurological system without any focal deficits. Her mini-mental state score was 22/30 with mild confusion. A scar from the previous thyroidectomy was visible on her neck. There were no parkinsonian features. The biochemical laboratory findings are given in Table 1.

A non-contrast CT scan revealed massive calcifications involving the basal ganglia, thalamus and cerebellar nuclei (Fig. 1).

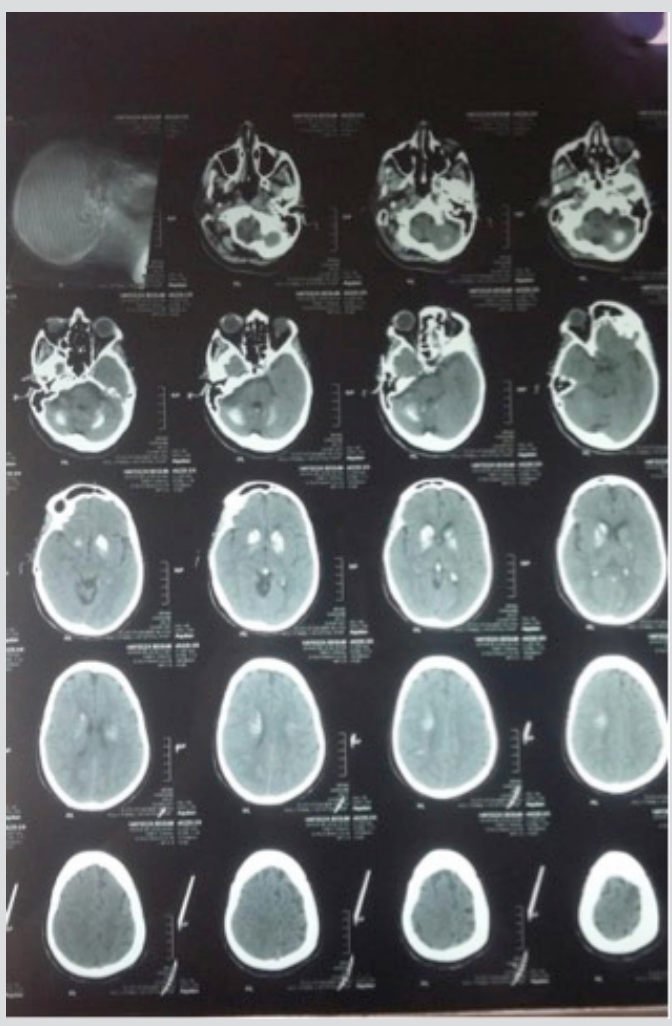

\begin{tabular}{|l|l|}
\hline Biochemical variables & Patient's value \\
\hline PTH $(15-65 \mathrm{pg} / \mathrm{ml})$ & $8.2 \mathrm{pg} / \mathrm{ml}$ \\
\hline Total calcium $(8.4-10.6 \mathrm{mg} / \mathrm{dl})$ & $5.4 \mathrm{mg} / \mathrm{dl}$ \\
\hline Urea (10-52 mg/dl) & $19 \mathrm{mg} / \mathrm{dl}$ \\
\hline Creatinine (up to $1.2 \mathrm{mg} / \mathrm{dl})$ & $0.9 \mathrm{mg} / \mathrm{dl}$ \\
\hline Phosphate $(2.3-4.7 \mathrm{mg} / \mathrm{dl})$ & $5.6 \mathrm{mg} / \mathrm{dl}$ \\
\hline
\end{tabular}

Figure 1. CT scan of the brain showing widespread intra-cranial calcification Table 1. Biochemical values

On the basis of clinical, laboratory and neurological findings, the patient was diagnosed with Fahr's disease secondary to post-thyroidectomy hypoparathyroidism. Upon consultation with the neurology clinic, she was started on oral calcium and vitamin D which resulted in some improvement.

\section{DISCUSSION AND CONCLUSION}

Fahr's disease, also known as Fahr's syndrome, is a rare degenerative neurological disorder. It is characterized by intracranial bilateral symmetrical calcification, particularly in the basal ganglia and dentate nucleus. These abnormal calcium deposits consist of calcium carbonate and calcium phosphate.

The specific aetiological agent for Fahr's disease has not yet been identified. The disease has autosomal dominant, and less commonly autosomal recessive, patterns of inheritance, with three loci suggested so far: chromosomes $14 \mathrm{q}, 2$ and $8^{[3]}$. Both sporadic and familial cases have been reported. Patients present with an array of clinical symptoms due to lack of full penetrance of the gene ${ }^{[4]}$. No relatives of our patient with similar neuropsychiatric symptoms were identified. Basal ganglia calcification is associated with conditions such as endocrine disorders (idiopathic, pseudo or secondary hypoparathyroidism), infections (intra-uterine or perinatal infections, brucellosis, toxoplasmosis, tuberculosis) and inherited syndromes (Aicardi-Goutieres syndrome, Coat's disease, tuberous sclerosis complex) ${ }^{[5]}$. 
In our case, the condition was found to be a complication of thyroidectomy. It has been postulated that calcium deposition starts approximately three decades before clinical symptoms appear.

Based on aetiology, two forms of Fahr's disease have been suggested: primary and secondary ${ }^{[6]}$. Primary Fahr's is the familial or sporadic type, while the secondary form is associated with metabolic or, more commonly, endocrine pathologies, as in our case $\mathrm{e}^{[7,8]}$.

Clinical symptoms usually appear in fourth to sixth decades of life, as in our patient. The spectrum of clinical expression is very wide and characterized by neurological, psychiatric and cognitive impairment. However, patients without these classic features have also been reported in the literature ${ }^{[9]}$.

Diagnosis requires the identification of calcium deposits in the brain by non-contrast CT scanning, which is preferred over MRI for defining calcified areas. A CT brain scan can also be performed as a pre-symptomatic test in unaffected family members. The diagnosis in our patient was based on a CT scan of the brain and low PTH levels. Diagnostic criteria for Fahr's disease are important as (a) they are helpful in cases of Fahr's disease with a negative family history and (b) there are several conditions which also show symmetrical basal ganglia calcification. The diagnostic criteria for Fahr's disease ${ }^{[6]}$ are listed below:

- Tomographic evidence of bilateral basal ganglia or other area calcification.

- Neuropsychiatric clinical symptoms with or without a degenerative course.

- Age of onset usually in the fourth to sixth decades of life.

- Absence of other causes of intra-cranial calcification.Absence of traumatic, infectious or toxic causes.

Definitive treatment for primary Fahr's has not been defined. However, correction of metabolic derangements such as low calcium or phosphorus levels, can result in some improvement, as in our case, and delay progression ${ }^{[10]}$. Other symptoms are usually treated symptomatically according to the brain area affected.

The patient we describe developed secondary hypoparathyroidism due to subtotal thyroidectomy performed 25 years previously which resulted in the development of Fahr's syndrome. Therefore, we recommend CT imaging and measurement of serum calcium levels as part of long-term follow-up of patients after thyroidectomy.

\section{REFERENCES}

1. Saleem S, Aslam HM, Anwar M, Anwar S, Saleem M, Saleem A, et al. Fahr's syndrome: literature review of current evidence. Orphanet J Rare Dis 2013;8:156.

2. dos Santos VM, Da Mata AM, Ribeiro KR, Calvo IC. Fahr's syndrome and secondary hypoparathyroidism. Rom J Intern Med 2016;54:63-65.

3. Lam JS, Fong SY, Yiu GC, Wing YK. Fahr's disease: a differential diagnosis of frontal lobe syndrome. Hong Kong Med J 2007;13(1):75-77.

4. de Oliveira DF, de Lemos RR, de Oliveira JRM. Mutations at the SLC20A2 gene and brain resilience in families with idiopathic basal ganglia calcification ("Fahr's disease"). Front Human Neurosci 2013;7:420.

5. Rahman AS, Ahmed S, Ahmed T, Husain T. Case report fahrs disease: a young girl presenting with fits. Pak J Pharmacol 2010;27(1):61-64.

6. Kumar S, Sher K, Ahmed S, Naik S, Ayub S, Motiwala FB, et al. Fahr's disease: a rare neurological disease frequently misdiagnosed as acute psychosis, or mood disorder. J Neurol Disord 2013;1(3):130.

7. Soaresa FB, Amorin FF, Santana AR, de Mourac EB, Margalho SB, Pontes Amorim AP, et al. Fahr's syndrome due to hypoparathyroidism following thyroidectomy. J Med Cases 2013;4:380-384.

8. Goswami R, Sharma R, Sreenivas V, Gupta N, Ganapathy A, Das S. Prevalence and progression of basal ganglia calcification and its pathogenic mechanism in patients with idiopathic hypoparathyroidism. Clin Endocrinol (Oxf) 2012;77(2):200-206.

9. Benke T, Karner E, Seppi K, Delazer M, Marksteiner J, Donnemiller E. Subacute dementia and imaging correlates in a case of Fahr's disease. J Neurol Neurosurg Psychiatry 2004:75(8):1163-1165.

10. Calili DK, Mutlu NM, Mutlu Titiz AP, Akcaboy ZN, Aydin EM, Turan IO. Unexplained neuropsychiatric symptoms in intensive care: a Fahr syndrome case. J Pak Med Assoc 2016;66(8):1029-1031. 